ASEAN Journal of Chemical Engineering 2021, Vol. 21, No. 1, $136-144$

\title{
Mathematical Model for Water Flooding and HPAM Polymer Flooding in Enhanced Oil Recovery
}

\section{Ahmad Tawfiequrrahman Yuliansyah* \\ Bardi Murachman \\ Suryo Purwono}

Department of Chemical Engineering, Universitas Gadjah Mada, Jln. Grafika No.2 Yogyakarta, Indonesia

*e-mail: atawfieq@ugm.ac.id

Submitted 28 April 2021

Revised 20 June 2021

Accepted 21 June 2021

\begin{abstract}
The need for energy, especially the petroleum-based one, is steadily increasing along with population growth and technological advancement. Meanwhile, oil exploitation from oil reservoirs using primary and secondary techniques can only obtain about $30 \%-50 \%$ out of the original oil in place. Enhanced Oil Recovery (EOR) is a method for increasing oil recovery from a reservoir by injecting materials that are not found in the reservoir, such as surfactant, polymer, etc. This research aims to develop a mathematical model representing two-phase flow through porous media in the EOR process. This model was extended from mass balance and fluid flow in porous media equations. The reliability of the model was then validated by water flooding and polymer flooding experiment. A porous media, constituted by a silica sand pack, was saturated with $2 \%$ brine and sequentially flooded with HPAM polymer solution at various concentrations $(5,000$ $15,000 \mathrm{ppm}$ ). The volume of the oil coming out from the media at any time intervals was measured. Validation of the model was carried out by optimizing the model parameters to obtain the best curve-fitting on the plot of the percentage of cumulative recovered oil against time. The results showed that the proposed mathematical model was reliable enough to express both water and polymer-flooding processes.
\end{abstract}

Keywords: Enhanced oil recovery, HPAM, Mathematical model, Polymer flooding, Water flooding

\section{INTRODUCTION}

Nowadays, petroleum has become the most prominent energy source since it is most readily used and converted into other forms of energy. Not surprisingly, the amount of oil reserve has been steadily diminishing because of continuous exploitation and use. For example, it was recorded that the Indonesian oil reserve at the end of 2017 was 3.2 thousand million barrels, which is decreased 20\% to its reserve in 2007 (British Petroleum, 2018). Meanwhile, oil exploration using the conventional method can only recover $20-40 \%$ out of original oil in place (OOIP). Therefore, approximately $60-80 \%$ oil is left in the actual reservoir (Abidin et al., 2012). Several techniques have been attempted to recover this remaining oil.

Enhanced oil recovery (EOR) is a nonconventional method for obtaining crude oil from mature and even abandoned oil fields. This technique is carried out by applying or injecting materials that are not originated from the reservoir itself. Based on the materials used, Lake et al. (2014) classified EOR into four methods: 
a. Thermal processes consist of steam stimulation, steam flooding, and in situ combustions;

b. Chemical processes include surfactant flooding, polymer flooding, and caustic flooding;

c. Miscible displacement processes comprise miscible hydrocarbon displacement, carbon dioxide injection, and inert gas injection ;

d. Others, such as microbial, electrical, chemical leaching, mechanical (vibrating, horizontal drilling) methods

In principle, these methods aim to alter oil composition, reservoir temperature, and or fluid-rock interaction properties to ease oil flow. In the oil recovery process, oil mobility is expected to be higher than that of injected water (solution). One of the methods to achieve this condition is by adding polymer into injected water (water phase). The presence of polymer in the water will reduce the water-oil mobility ratio by two mechanisms, e.g., raising viscosity and decreasing permeability of the water phase. Several polymer flooding studies (Wang et al., 2001; Xia et al., 2004; Yin et al., 2006; Zhang et al.; 2008) have shown that more oil recovered and shorter time required (compared to water flooding). In general, polymer flooding can increase the oil recovery by $5-30 \%$ of OOIP (Pope, 2007). Furthermore, Rellegadla et al. (2017) has reported that more than $77 \%$ of the chemical EOR project worldwide applied polymer, and the rest used a combination of polymersurfactant.

The two most common polymers used in EOR are biopolymer (polysaccharide type, xanthan) and synthetic polymers (such as polyacrylamide). Polyacrylamide is a longchain polymer of acylamide with high solubility in water but is not soluble in alcohol, ether, ester, toluene, and benzene (Kirk and
Othmer, 2007). Partially-hydrolyzed polyacrylamide (HPAM) is a polyacrylamide polymer with a partially hydrolyzed amide group. The viscosity of this HPAM solution varies depending on the percent of hydrolysis (Hasegawa, 1976). In addition, HPAM is hygroscopic and water-soluble.

Compared to other types of polymer, HPAM has several advantages. It is less costly, more resistant to microbial attack, and reduces water phase permeability permanently. However, it is sensitive to salinity, hardness, and mechanical degradation, particularly in high pressure and high flowrate operation mode (Abidin et al., 2012). Nevertheless, by far, HPAM has been the most often used synthetic polymer in field-scale of EOR applications (Firozjaii et al., 2020).

Several factors that must be considered in EOR with polymer flooding are the structure and characteristics of porous media (reservoir), the fluid in the reservoir, and effect of the polymer on fluid flow, and residual oil mobility. Thus, the fluid flow inside a reservoir during EOR flooding involves a complex mechanism that is hard to predict (Noraishah et al., 2020).

Several mathematical models have been developed to describe the polymer flooding mechanism in the reservoir (Hatzignatiou et al. 2013; Wang et al. 2013; Dang et al. 2015; Borazjani et al. 2016; Davarpanah et al. 2019; Vicente et al. 2020). However, most of the models are complex and tricky. Hence, a simple mathematical model, but reliable and adequately accurate in representing the polymer flooding of EOR, is required. This research aims to develop a modest mathematical model for water flooding and HPAM polymer flooding in the EOR process. Hence, a mixture of oil-brine water and polymer solution flown in a simulated 
reservoir is considered one-dimensional twophase flow through porous media.

\section{MATERIALS AND METHODS}

\section{Mathematical Model}

The mathematical model used for polymer flooding is a modified model for one-dimensional two-phase flow through porous media proposed by Budiaman (1994). Hence, the polymer flooding was done sequentially after water flooding. The fluid flow (q) in the media is schematically illustrated in Figure 1.

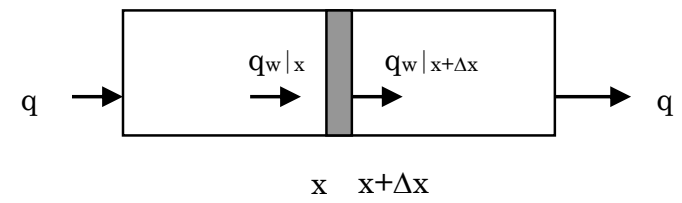

Fig. 1: Fluid flow in the element volume

The following assumptions have been applied in the mathematical modeling: flow pattern of the fluid is plug flow, superficial velocity is constant, the temperature is kept homogeneous constant, and the polymer is present only in the water phase. By applying mass conservation of brine water and polymer solution, as well as the flow equations in the porous media, the obtained governing equations for this model are as follows:

\section{a. Water Flooding Step}

Water saturation $\left(S_{w}\right)$ in the element volume as a function of position $(x)$ and time $(t)$ is expressed in Eq. (1).

$$
\frac{\partial S_{w}}{\partial t}=-\frac{u}{\phi} \frac{d f_{w}}{d S_{w}} \frac{\partial S_{w}}{\partial x}
$$

The volume fraction of water $\left(f_{w}\right)$ in the fluid flow is defined by Eq. (2).

$$
f_{w}=\frac{1}{1+\frac{(1-S)^{n_{2}}}{\Omega^{0} \cdot S^{n_{1}}}}
$$

where $\Omega^{0}$ is the water-oil mobility ratio at the endpoint, and $n_{1}, n_{2}$ are constants. Meanwhile, a saturation of the porous media $(S)$ is defined in Eq (3).

$$
S=\frac{S_{w}-S_{w r}}{1-S_{w r}-S_{o r . w}}
$$

According to Eq. (3), the saturation of the porous media (S) depends on water saturation $\left(S_{w}\right)$, residual water saturation $\left(S_{w r}\right)$, and residual oil saturation at the water flooding step (Sor,w). Moreover, water saturation and oil saturation summation should be a unit, as written in Eq. (4).

$$
S_{w}+S_{o}=1
$$

Boundary conditions required to solve those abovementioned equations are:

$$
\begin{array}{crr}
t=0 & 0 \leq x \leq L & S_{w}=S_{w 0} \\
t>0 & x=0 & S_{w}=1
\end{array}
$$

\section{b. Polymer Flooding Step}

In the polymer flooding step, the HPAM polymer solution is introduced to the core at $x=0$. The concentration of polymer $(C p)$ along the core as the function of position $(x)$ and time (t) is expressed in Eq. (7).

$$
D_{e} \frac{\partial^{2} C p}{\partial x^{2}}-u f_{w} \frac{\partial C p}{\partial x}=\phi S w \frac{\partial C p}{\partial t}
$$

The presence of the HPAM polymer also changed the water saturation (Eq. (8)). 


$$
\frac{\partial S_{w}}{\partial t}=-\frac{u}{\phi}\left\{\frac{\partial f_{w}}{\partial S_{w}} \frac{\partial S_{W}}{\partial x}+\frac{\partial f_{w}}{\partial C_{p}} \frac{\partial C_{p}}{\partial x}\right\}
$$

The volume fraction of water $\left(f_{w}\right)$ in this step is similar to that in the water flooding step (Eq. (3)). Analogously, the saturation of the porous media (S) in this step is defined as:

$$
S=\frac{S_{w}-S_{w r}}{1-S_{w r}-S_{o r . p}}
$$

Meanwhile, residual oil saturation at polymer flooding step (Sor,p) and water-oil mobility $\left(\Omega^{0}\right)$ is assumed proportionally reduced by increased concentration of HPAM polymer, expressed in Eq. (10) and Eq. (11).

$$
\begin{aligned}
& S_{o r, p}=S_{o r, w}-a_{1} \cdot C_{p} \\
& \Omega^{0}=\Omega_{w f}^{0}-a_{2} \cdot C p
\end{aligned}
$$

Boundary conditions for solving Eq. (7)-(11) are:

$$
\begin{aligned}
& t=0 \quad 0 \leq x \leq L \quad S_{w}=S_{w 0} ; C p=0 \\
& t>0 \quad x=0 \quad \frac{\partial S w}{\partial x}=0 ; C p=C p_{\text {in }}
\end{aligned}
$$

All the equations are solved simultaneously with a numerical method using computer programming. Multivariable optimization by minimizing the sum square of errors (SSE) is applied to determine $\Omega^{0}{ }^{w} f_{,}$ $\mathrm{n}_{1}, \mathrm{n}_{2}, D_{e}, \mathrm{a}_{1}$, and $\mathrm{a}_{2}$. The equations for SSE calculation are as follows:

$$
V_{o i}=\phi \cdot A \int_{0}^{L}\left(1-S_{w}(x, 0)\right) d x
$$

$$
\begin{aligned}
& V_{o r}=\phi \cdot A \int_{0}^{L}\left(1-S_{w}(x, t)\right) \cdot d x \\
& V_{o p}=\frac{V_{o i}-V_{o r}}{V_{o i}} \times 100 \% \\
& P V I=\frac{u \cdot A \cdot t}{\phi \cdot A \cdot L} \\
& S S E=\sum_{i=1}^{n}\left\{\left(V_{o p}\right)_{c a l c}-\left(V_{o p}\right)_{\text {data }}\right\}^{2}
\end{aligned}
$$

where $V_{o i}, V_{o r}$, and $V_{o p}$ are the volume of initial oil, residual oil, and recovered oil volume, respectively, calculated based on the model. Meanwhile, the volume of fluid that has been injected for a specific time $(t)$ is determined relative to the pore volume of the core (denoted as PVI, pore volume injected). $P V I$ is a function of the superficial velocity of the fluid $(u)$ and the core properties (cross-sectional area $(A)$, length $(L)$, and porosity $(\phi))$.

Flooding experiments using an artificial reservoir (silica sand pack) have been conducted to validate the model. The data collected from the experiments were then compared with that obtained from computer simulation.

\section{Flooding Experiment}

\section{Materials}

In this experiment, an artificial reservoir (porous media) was prepared by loading silica sandstone into a core holder, and it was pressed using a hydraulic press approximately at $15,000-20,000 \mathrm{~kg} / \mathrm{m}^{2}$. Afterward, its porosity and permeability were measured.

For flooding experiment, crude oil from Kawengan field is used. Properties of the crude oil are as follows: viscosity $\left(50{ }^{\circ} \mathrm{C}\right)=$ $3.1856 \mathrm{cP}$, density $\left(50{ }^{\circ} \mathrm{C}\right)=0.8365 \mathrm{~g} / \mathrm{cm}^{3}$, pour point $=75^{\circ} \mathrm{F}$, and water content $=0 \%$. 
On the other hand, brine water solution (viscosity $\left(50^{\circ} \mathrm{C}\right)=0.5763 \mathrm{cP}$ and density $(50$ $\left.{ }^{0} \mathrm{C}\right)=0.9895 \mathrm{~g} / \mathrm{cm}^{3}$ ) is used for injecting water. For polymer flooding, HPAM polymer solution (5,000 - 15,000 ppm) was employed with properties described in the Table 1.

Table 1. Properties of HPAM polymer solution

\begin{tabular}{ccc}
$\begin{array}{c}\text { HPAM } \\
\begin{array}{c}\text { concentration, } \\
\mathbf{p p m}\end{array}\end{array}$ & $\begin{array}{c}\text { Viskosity } \\
\left(\mathbf{5 0} \mathbf{}^{\circ} \mathbf{C}\right), \mathbf{c P}\end{array}$ & $\begin{array}{c}\text { Density } \\
\left(\mathbf{5 0} \mathbf{~}^{\circ} \mathbf{C}\right) \\
\mathbf{g} / \mathbf{c m}^{\mathbf{3}}\end{array}$ \\
\hline 5,000 & 0.9047 & 0.9790 \\
10,000 & 1.3608 & 0.9831 \\
15,000 & 1.4389 & 0.9854 \\
\hline
\end{tabular}

\section{Apparatus}

Apparatus for water flooding and polymer flooding experiment is schematically illustrated in Figure 2.

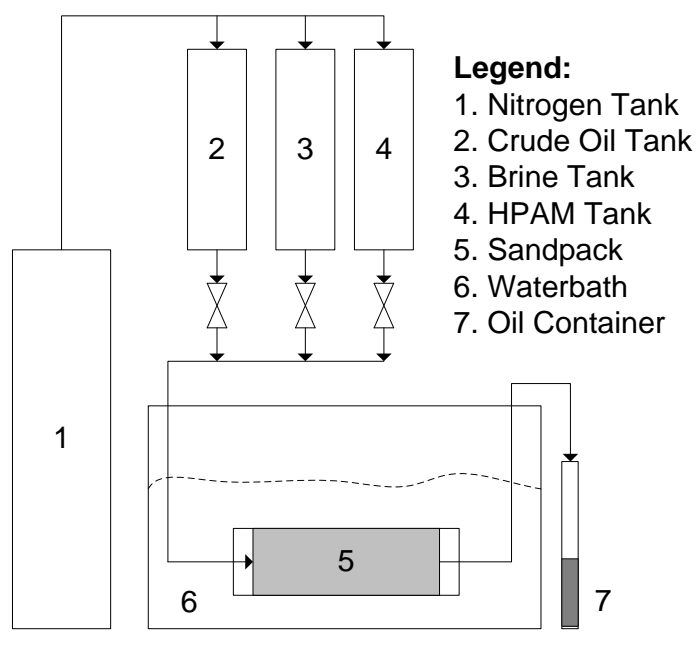

Fig. 2: Set of apparatus for flooding experiment

\section{Procedure}

Porous media (in a stainless-steel cylinder, $I D=3.8 \mathrm{~cm}, L=15 \mathrm{~cm}$ ) was saturated with $2 \%$ brine solution, followed by crude oil. For an indicator, the saturated condition was achieved when the volumetric flow rate of fluid coming out from the media was equal to that injected into the media. Afterward, the water flooding was carried out by injecting brine water solution to the media until no crude oil flowed out anymore. Then, the polymer flooding was started by injecting HPAM polymer solution into the media. The volume of the oil coming out from the core media in time intervals, both for water flooding and polymer flooding, was recorded.

\section{RESULTS AND DISCUSSION \\ Effect of HPAM polymer flooding on oil recovery}

Experimental data for the flooding experiment, both water flooding and polymer flooding (using various concentrations of HPAM solutions), were presented in Table 2. The obtained incremental oil recovery is also shown in this table.

It was shown in Table 2 that using a higher concentration of HPAM increased the incremental oil recovery due to the higher viscosity of the polymer that reduced more the water-oil mobility ratio.

As a result, residual oil trapped in porous media is easier to come out and increases oil recovery. Based on the experimental data, the highest oil recovered is $17.18 \%$ to the residual oil after water flooding.

\section{Simulation results}

The experimental data obtained were in the form of the cumulative volume of the recovered oil vs. time. These data were then compared with the oil recovery simulation data of the proposed mathematical model. The parameters of $\Omega^{0}{ }_{w f}, n_{1}, n_{2}, D_{e}, a_{1}$, and $a_{2}$ were numerically optimized to give minimum SSE. The parameters $\Omega^{0}{ }_{w f}, n_{1}, n_{2}$ were determined in the water flooding step, while 
the parameter $\mathrm{De}$, a1 and a2 were resolved for polymer flooding.

Table 2. Condition for flooding experiment

\begin{tabular}{|c|c|c|c|c|c|c|c|c|c|}
\hline \multirow{2}{*}{ No } & \multirow{2}{*}{$\begin{array}{l}\text { HPAM } \\
\text { concentr } \\
\text { ation, } \\
\text { ppm }\end{array}$} & \multirow{2}{*}{$\begin{array}{c}\text { Porosity } \\
\text { of } \\
\text { media, } \\
\%\end{array}$} & \multicolumn{2}{|c|}{$\begin{array}{l}\text { Superficial velocity } \\
\text { of fluid, } \mathrm{cm} / \mathrm{s}\end{array}$} & \multicolumn{2}{|c|}{ Flooding Time, S } & \multicolumn{3}{|c|}{ Recovery, \% } \\
\hline & & & $\begin{array}{c}\text { Water } \\
\text { Fooding }\end{array}$ & $\begin{array}{l}\text { Polymer } \\
\text { Flooding }\end{array}$ & $\begin{array}{l}\text { Water } \\
\text { Fooding }\end{array}$ & $\begin{array}{l}\text { Polymer } \\
\text { Flooding }\end{array}$ & $\begin{array}{l}\text { Water } \\
\text { Fooding }\end{array}$ & $\begin{array}{l}\text { Polymer } \\
\text { Flooding*) }\end{array}$ & Total \\
\hline 1. & 5,000 & 41.43 & $1.44 \mathrm{E}-03$ & $1.58 \mathrm{E}-03$ & 5,760 & 3,360 & 70.76 & 8.40 & 73.22 \\
\hline 2. & 10,000 & 39.79 & $1.21 \mathrm{E}-03$ & $1.37 \mathrm{E}-03$ & 10,800 & 9,600 & 53.70 & 14.62 & 60.47 \\
\hline 3. & 15,000 & 25.70 & $1.10 \mathrm{E}-03$ & $1.06 \mathrm{E}-03$ & 9,600 & 10,800 & 52.85 & 17.18 & 60.95 \\
\hline
\end{tabular}

A comparison of the experimental oil recovery data and the simulation data was shown in Figure 3. The dashed line on the figure represented the transition of the water flooding to the polymer flooding.

In the HPAM 5,000 ppm experiment, the effect of HPAM flooding on cumulative oil recovery was not significant. Only $8.40 \%$ of residual oil was recovered in the polymer flooding step. It was caused most of the oil (70.76 \% of OOIP, original oil in place) had been recovered in the preceding step (water flooding step). Therefore, the presence of HPAM 5,000 ppm solution in the polymer flooding did not affect much.

This effect was also reflected from the viscosity difference between the solutions used in water flooding, and polymer flooding was relatively minor $(0.5763 \mathrm{cP}$ and $0.9047 \mathrm{cp}$, for water flooding and polymer flooding, respectively).

Figure 3(b) shows that the incremental oil recovery caused by polymer flooding of HPAM 10,000 ppm was visible. In this experiment, the viscosity of the polymer solution was sufficient to push out residual oil from the porous media. As a result, the oil recovery increased. Compared with the 5,000-ppm experiment, the time for flooding was longer because the porosity of the media is smaller, so the superficial velocity of the fluid in the media was also lower.

Experimental results on HPAM 15,000 ppm (Fig. 3(c)) showed that increased incremental oil recovery by polymer flooding is more significant. Compared with HPAM 10,000 ppm, the incremental oil recovery was higher; however, their difference is not much $(14.62 \%$ vs. $17.18 \%)$. This variance was probably due to the viscosity difference of the HPAM solution used was relatively similar (1.3608 cP vs. 1.4389 cP). The water-oil mobility ratios for these two runs of the experiment were also identical. Furthermore, the porosity of the media of run No.3 was the smallest among the others.

Figure 3 shows that the experimental data were fit enough with the simulation data. However, in some parts of the cumulative oil recovery curve, particularly in the polymer flooding, the simulation data were almost consistently lower than the experimental data. Nonetheless, such two sets of data had similar trends. Since the differences were less than $10 \%$ (relative to the experimental data values), these differences were practically insignificant. This fact reflects that the proposed mathematical model is adequately reliable. The model parameters obtained by computer simulation are listed in Table 3.

Since the mathematical model has been developed from fundamental equations for 
fluid flow, its use is not only limited to HPAM polymer, but also applicable to other polymers. However, the model's suitability for different types of stone should be further examined due to the complex mechanism of interaction between polymer fluid and stone, which may differ from one type of stone to another.

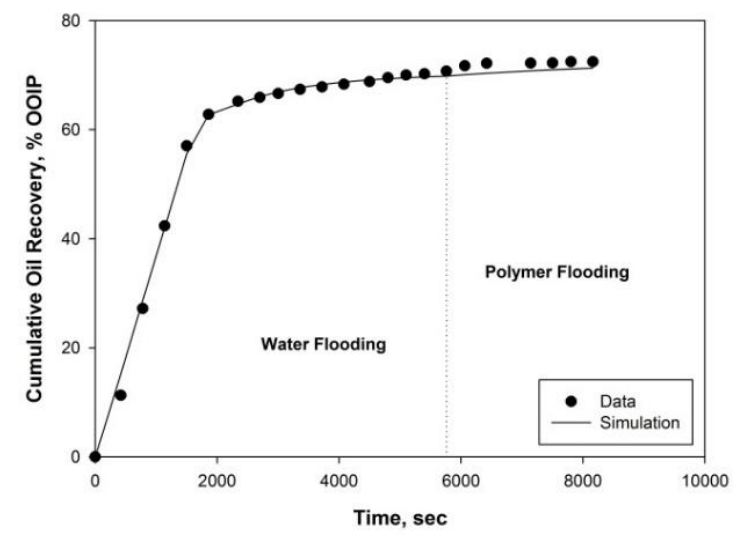

(a)

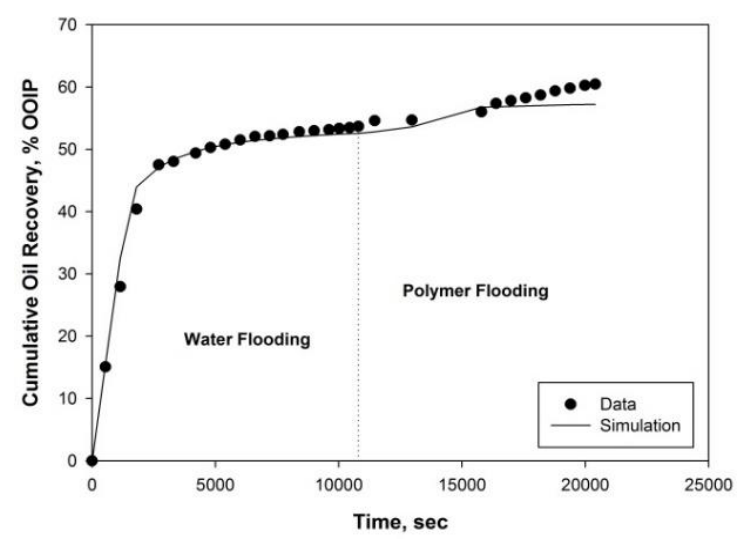

(b)

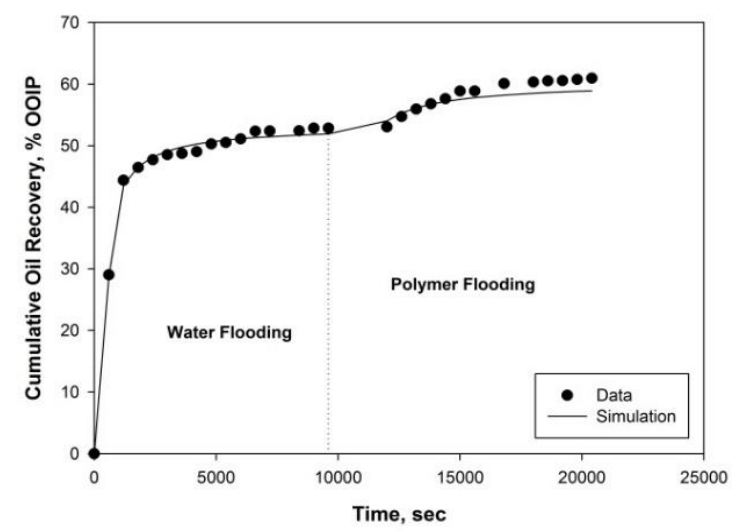

(c)

Fig 3: Cumulative oil recovery at flooding experiments with HPAM (a) 5,000 ppm; (b) $10,000 \mathrm{ppm}$; (c) $15,000 \mathrm{ppm}$

Table 3. Parameter of the mathematical model

\begin{tabular}{|c|c|c|c|}
\hline \multirow{2}{*}{ Parameter } & \multicolumn{3}{|c|}{ Concentration of HPAM, ppm } \\
\hline & 5,000 & 10,000 & 15,000 \\
\hline \multirow{3}{*}{ 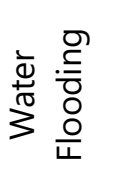 } & 1.249 & 1.218 & 1.017 \\
\hline & 1.367 & 1.686 & 1.854 \\
\hline & 1.472 & 1.531 & 1.212 \\
\hline \multirow{3}{*}{ 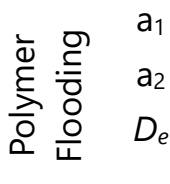 } & 1.840 & 3.624 & 3.536 \\
\hline & 20.3 & 17.869 & 16.327 \\
\hline & $3.04 \mathrm{E}-05$ & $7.39 \mathrm{E}-05$ & 3.97E-05 \\
\hline Average & 2.51 & 2.12 & 2.38 \\
\hline
\end{tabular}

\section{CONCLUSIONS}

On the laboratory scale, the use of HPAM polymer solution as injecting material has the potential to raise the oil recovery. Higher oil recovery was achieved on a higher concentration of HPAM. Polymer flooding with HPAM 15,000 ppm increases oil recovery as high as $17.18 \%$ of residual oil. Furthermore, both the water flooding and polymer flooding process could be well represented by the proposed model.

\section{REFERENCES}

1. Abidin, A. Z., Puspasari, T., and Nugroho, W.A. (2012). "Polymers for enhanced oil recovery technology," Procedia Chemistry, 4, 11-16.

2. Borazjani, S., Bedrikovetsky, P., and Farajzadeh, R. (2016). "Analytical solutions of oil displacement by a polymer slug with varying salinity," J. Pet. Sci. Eng., 140, 28-40

3. Budiaman, I. G. S. (1994). Onedimensional two-phase flow on enhanced 
oil recovery using immiscible chemical flooding (In Bahasa Indonesia), Thesis, Department of Chemical Engineering, Gadjah Mada University, Yogyakarta, Indonesia.

4. British Petroleum. (2018). BP Statistical Review of World Energy; June 2018.

5. Dang, T. Q. C., Chen, Z., Nguyen, T. B. N., and Bae, W. (2015). "Rheological Modeling and Numerical Simulation of HPAM Polymer Viscosity in Porous Media," Energy Sources, Part A: Recovery, Utilization, and Environmental Effects, 37:20, 2189-2197.

6. Davarpanah, A. and Mirshekari, B. (2019). "A mathematical model to evaluate the polymer flooding performances," Energy Reports, 5, 1651-1657.

7. Firozjaii, A. M., Akbari, M., and Zargar, G. (2019)." Sensitivity analysis and optimization on effective parameters during chemical enhanced oil recovery (CEOR) using experimental design and numerical simulation," Energy Sources, Part A: Recovery, Utilization, and Environmental Effects, 41:15, 1847-1861.

8. Hasegawa, M., Furuno, A., Ishikawa, H., and Ogawa, Y. (1976). U. S. Pat. 3986093.

9. Hatzignatiou, D. G., Norris, U. L., and Stavland, A. (2013). "Core-scale simulation of polymer flow through porous media," J. Pet. Sci. Eng., 108, 137150.

10. Kirk, G. W., and Othmer, D. F. (2007). Encyclopedia of chemical technology, 5th edition, John Wiley and Sons, New York, U. S. A.

11. Lake, L. W., Johns, R., Rossen, B., and Pope, G. (2014). Fundamentals of Enhanced Oil Recovery, Society of Petroleum Engineers, TX, USA.

12. Noraishah, Saaid, I. M., Ahmed, A., Yusof, N. H., Yahya, R., Yunos, M. A. S. M., Chik,
E. M. F. E., Shari, M. R., Hassan, H., and Mahmood, A. A. (2020). "Investigation of Water-Flooding Activity Using Radiotracer Technology in Commercial Core-Flood Set Up," ASEAN J. Chem. Eng., 20(1), 49-56.

13. Pope, G. A. (2007). Overview of chemical EOR, Casper EOR Workshop, The University of Texas, Austin, U. S. A.

14. Rellegadla, S., Prajapat, G., and Agrawal, A. (2017). "Polymers for enhanced oil recovery: fundamentals and selection criteria," Appl Microbiol Biotechnol, 101, 4387-4402.

15. Vicente, B.J., Priimenko, V.I., and Pires, A.P. (2020). "Mathematical Model of Water Alternated Polymer Injection." Transp Porous Med., 135, 431-456.

16. Wang, J., Liu, H.Q., and $X u$, J. (2013). "Mechanistic Simulation Studies on Viscous-Elastic Polymer Flooding in Petroleum Reservoirs," J. Dispersion Sci. Technol., 34:3, 417-426.

17. Wang, D., Xia, H., Liu, Z., and Yang, Q. (2001, April 17-19). "Study of the mechanism of polymer solution with visco-elastic behavior increasing microscopic oil displacement efficiency and the forming of steady "oil thread" flow channels." SPE - Asia Pacific Oil and Gas Conference, Jakarta, Indonesia.

18. Xia, H., Ju, Y., Kong, F., and Wu, J. (2004, September 26-29). "Effect of elastic behavior of HPAM solutions on displacement efficiency under mixed wettability conditions." SPE - Annual Technical Conference and Exhibition, Houston, Texas, U. S. A.

19. Yin, H., Wang, D., and Zhong, H. (2006, September 24-27). "Study on flow behaviors of viscoelastic polymer solution in micropore with dead end." 
SPE - Annual Technical Conference and

Exhibition, San Antonio, Texas, U. S. A.

20. Zhang, L., Yue, X., and Guo, F. (2008).

"Micro-mechanisms of residual oil mobilization by viscoelastic fluids," Pet. Sci., 5, 56-61. 